\title{
A MULTIVARIATE MODEL FOR FLOOD FORECASTING OF LAKE LEVELS
}

\author{
M. MOHSSEN \\ Department of Environmental Management, Faculty of Environment, Society and Design, Lincoln University, \\ Lincoln 7647, New Zealand.
}

\begin{abstract}
A new multivariate model for flood forecasting of lake levels has been developed and applied to Lake Wakatipu and Lake Wanaka in the South Island of New Zealand. The model is based on the concept of the projection theorem to derive the optimum projection of the increase in lake levels on the driving factors for this increase. The driving factors that have been considered in this research are observed rainfall at sites in the catchment area or close to it, stream flows from rivers draining this rainfall in the region and outflows from the lakes. About 22 years of observed rainfall, river flows, lake outflows and lake levels have been investigated to select 23 significant events for model calibration and 2 events for model validation. A lag of 10 hours (Lake Wakatipu) and a lag of 7 hours (Lake Wanaka) between cumulative lake rise and cumulative rainfalls have been verified to improve the modelling process and have been utilized in the multivariate model. The analysis of the fitted parameters for the multivariate model has resulted in the removal of some sites from the model due to their insignificant contribution or their being on odd with the realistic physical hydrological process. The projection theorem for orthonormal sets in the Hilbert space has been applied to the statistical characteristics of the data to estimate the optimum parameters of the multivariate model. Two multivariate models have been developed in this research. The first multivariate model is for the long-term forecast of the rise of lake levels based on the forecasted rainfalls at selected rainfall sites in the catchment. The second multivariate model was derived based on the physical process of the hydrologic budget of a catchment and can be used for forecasted lake rise during the flood event based on rainfalls and stream flows gauged in the catchment areas of the lakes, in addition to the lake outflows.

Keywords: Lake level, flood forecast, flood modelling, Hilburt Space, lagged-correlations, projection theorem, rainfall-runoff, regression analysis.
\end{abstract}

\section{INTRODUCTION}

Floods are the most common natural disasters, and they cause devastating damage to communities. In the absence of flood protection infrastructures, flood warning is one of the most effective schemes to mitigate the impact of these natural hazards. The Environment Agency of UK and the strategic plan for the US National Weather Service indicated the urgent need for major investment to develop new forecast models for flood warning [1,2].

A reliable flood forecast model is the most important component of an efficient flood warning system. If reliable estimates of flood levels are forecasted before the event happens, authorities/communities can have sufficient time to mitigate the impact of the coming flood event by getting prepared, evacuating, moving stock away from flood-prone areas and relocating precious items. Despite the fact that literature is rich with research on flood forecasting, a large number of these models/techniques fail to accurately forecast flood events on the shorter scale (hourly) due to the high variability of the associated hydrological and meteorological processes [1]. High variability of precipitation, the main driving factor for floods, along with a complex hydrological characteristic of the catchment area, makes it difficult to obtain the right variables representing these processes at the right resolution to be capable of producing a reliable flood estimate of an occurring or incoming event. 
Despite the fact that the hydrologic process of lake flooding is quite different from that of river floods, the available modelling approaches in the literature are still similar. Watershed modelling is used to simulate the inflows to the lake, and then a hydrologic budget model is applied to translate the difference between inflows and outflows to a rise (or drop) in lake level [3, 4].

The time series modelling, using the autoregressive integrated moving average models, has been applied in the literature; however, due to the stationary requirement of the modelling process, usually they apply to longer time periods (days or more), while during flood events we are usually concerned in hourly flows [5]. Artificial neural network has been recently applied to forecast lake levels, and several techniques have been suggested for their applications to hourly time steps [6-11].

Floods are the most damaging and costly natural hazard in New Zealand, with 935 damaging flood events occurred during the period 1920-1983 [12]. Queenstown, a major town by Lake Wakatipu, which is full of attractions for tourism, has been badly flooded during the events of 1878 and 1999. Flooding of Lake Wakatipu takes long time (could be weeks) to recede, and this will have persistent impact on the economic activity of Queenstown township and its community. Lake Wanaka, $\sim 60 \mathrm{~km}$ north-east of Queenstown has also flooded the township of Wanaka, which is on the lake front.

Lake Wakatipu is New Zealand's third largest lake and is located immediately to the east of the Southern Alps in the western ranges of the Otago region in the South Island of New Zealand. The lake has a surface area of $293 \mathrm{~km}^{2}$ and a total catchment area of $3059 \mathrm{~km}^{2}$. The lake is $\sim 80 \mathrm{~km}$ long, whereas its widest section is $\sim 5 \mathrm{~km}$, and can reach a depth of $100 \mathrm{~m}$ [13].

Lake Wanaka has an area of $\sim 196 \mathrm{~km}^{2}$ and its catchment is also in the western ranges of Otago with an area of $2564 \mathrm{~km}^{2}$. Lake Wanaka discharges its outflows to the head of the Clutha River, which is the largest river in New Zealand with average flows of $534 \mathrm{~m}^{3} / \mathrm{s}$, whereas Lake Wakatipu outflows to the Kawarau River, which joins the Clutha River further downstream. Figure 1 shows the two lakes, their outflows and the location of rainfall sites of this study.

Flood hazards in the form of increased lake levels pose a threat to Queenstown and Wanaka townships, which are located on Lake Wakatipu and Lake Wanaka fronts. Inundation from

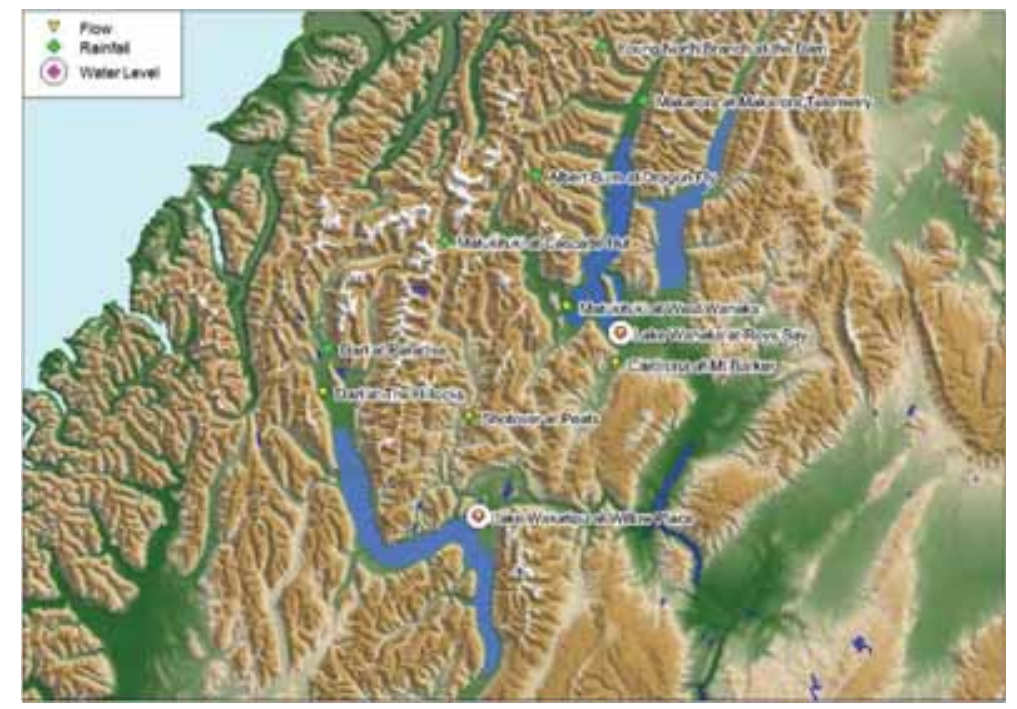

Figure 1: The catchments of Lake Wakatipu and Lake Wanaka. 
high lake levels can last for longer duration as the lakes can remain at high levels for periods measured in days and weeks. The level of Lake Wakatipu varies through a range of $\sim 3.9 \mathrm{~m}$ with a mean level of $\sim 310 \mathrm{~m}$ a.s.l. The flood of November 1999 was the highest lake level on record at $312.77 \mathrm{~m}$ a.s.l. [13] with the flood of September 1878 staying as the second at $312.60 \mathrm{~m}$ a.s.1.

\section{THE MULTIVARIATE FORECAST MODEL FOR LAKE LEVELS}

\subsection{Hydrological sites}

The rainfall sites for the catchment areas of Lake Wakatipu and Lake Wanaka, which are used in this research, are summarized in Table 1.

It is clear from Table 1 that some sites started later than others, and they will miss some of the important events, especially the November 1999 flood event that flooded Queenstown and resulted in significant damage and losses to the business in this famous tourism township. The analyses and modelling for this research have included all sites, but only results for the sites with sufficiently long record (the Hillocks, Peats Hut, Makarora and West Wanaka) will be presented here.

Lake Wakatipu outflows are recorded at Willow Place, whereas the site for Lake Wanaka outflows is at Roys Bay and are shown in Fig. 1. The third lake 'Lake Hawea' lies just to the east of Lake Wanaka and was not included in this study as it is completely controlled, and there is no major settlement or risk of flooding around the lake.

Lake flooding is different from river flooding as the lake has a huge storage and its outflows are a function of its level rather than inflows to the lake. Thus lake's rise is a function of cumulative rainfall over a period of time rather than its intensity during a short period of the rainfall event [13]. The new concept for modelling, which has been applied in this research, uses the projection theorem [14] to obtain the projection of the total rise of lake levels on the cumulative rainfall of the selected rain gauges. The projection theorem guarantees that the obtained model will produce the best forecasted flood levels, if a correct function that relates the time series was selected. The work carried out here is an extension of the univariate case presented by Mohssen and Goldsmith [13], where Lake Wakatipu levels were estimated by rainfall at only one rainfall gauging site (the Hillocks). In this research, multiple rainfall sites will be used to forecast lake levels at two lakes (Wakatipu and Wanaka)

Table 1: The rainfall sites in the region of Lake Wakatipu and Lake Wanaka.

\begin{tabular}{llcc}
\hline Site & Observer & The start of operation & Elevation (m) \\
\hline The Hillocks (H) & ORC & $21 / 08 / 1997$ & 353 \\
Cascade Hut (C) & ORC & $18 / 06 / 2003$ & 438 \\
Peat's Hut (P) & ORC & $19 / 12 / 1996$ & 480 \\
Paradise (Par) & ORC & $5 / 05 / 2003$ & 400 \\
West Wanaka (W) & NIWA & $9 / 01 / 1998$ & 300 \\
Makarora (M) & ORC & $4 / 11 / 1997$ & 320 \\
Albert Burn (A) & ORC & $21 / 04 / 2004$ & 1300 \\
\hline
\end{tabular}




\subsection{Model formulation}

For large lakes, such as Wakatipu and Wanaka, flooding will be slow and flood levels are more dependent on the cumulative rain rather than on the rainfall intensity, and usually peak flood levels recede slowly as the lake outlet takes long time to dispose the huge amount of water stored in the lake during the flood event. An hourly hydrologic balance for a lake, in the univariate case, can be expressed as follows [13]:

$$
L_{t+t_{f}}=L_{t-t_{1}}+\sum_{j=t-t_{1}}^{j=t+t_{f}-1} I_{j}-\sum_{j=t-t_{1}}^{j=t+t_{f}-1} Q_{j}
$$

Assuming that at the start of the rainfall event $t=0$, then $L_{t}$ is the lake level (mm) at the present time $t, t_{f}$ is the forecast time in hours after $t, t_{1}$ is a lag time (hours) before $t, Q_{j}$ is the lake outflow (mm) at time $j$ and $I_{j}$ is the inflow to the lake (mm) at time $j$.

Mohssen and Goldsmith [13], by analysing the 1999 flood event, showed that the best value for $t_{1}$ is the present time $t$; thus $t-t_{1}=0$, which is the start of the rainfall event. Level $L_{0}$ at the start of the event is usually used to obtain the rise of the lake level. Thus, eqn 1 can be expressed as follows:

$$
L_{t+t_{f}}=L_{0}+\sum_{j=0}^{j=t+t_{f}-1} I_{j}-\sum_{j=0}^{j=t+t_{f}-1} Q_{j}
$$

Let us denote the forecasted total lake rise since the start of the event $L_{t+t_{f}}-L_{0}$ as $\Delta L$, the cumulative inflow $\sum_{j=0}^{j=t+t_{f}-1} I_{j}$ as $\Delta I$ and the cumulative outflow since the start of the event $\sum_{j=0}^{j=t+t_{f}-1} Q_{j}$ as $\Delta Q$, then eqn 2 in the multivariate form is expressed as follows:

$$
\left[\begin{array}{c}
\Delta \boldsymbol{L}_{1} \\
\Delta \boldsymbol{L}_{2}
\end{array}\right]=\left[\begin{array}{c}
\Delta \boldsymbol{I}_{1} \\
\Delta \boldsymbol{I}_{2}
\end{array}\right]-\left[\begin{array}{c}
\Delta \boldsymbol{Q}_{1} \\
\Delta \boldsymbol{Q}_{2}
\end{array}\right]
$$

where subscripts 1 and 2 refer to Lake Wakatipu and Lake Wanaka, respectively. The total lake inflows during a flood event are difficult to measure or know, due to the fact that there are a large number of unmeasured streams that drain directly to the lake, in addition to the direct surface runoff from some areas adjacent to the lake. Add to this the accuracy in the rated flows during significant flood events. The observed rainfalls at gauged sites are very useful for point precipitation, but to know areal rainfall over the whole catchment is a quite challenging task. There are several techniques to estimate areal precipitation from point values, but the accuracy will depend on the number of gauging sites available and the validity of the assumptions associated with these techniques, especially in a quite diverse, steep and mountainous terrain as the catchment areas for both lakes under study. In the model presented here, the cumulative inflow to the lake will be assumed to be a function of the cumulative point rainfall at the available gauging sites, in addition to a function of cumulative flows of the main rivers draining these catchments and going to the lake. The flows of these rivers represent a good indication of the areal precipitation over the catchment areas and the hydrological abstractions associated with this rain. Mohssen and Goldsmith [13] showed that using the total lake inflows as the sum of the outflows and the lake rise does not result in improving the reliability of the forecast model for the univariate case; in contrast, model testing showed that it resulted in less reliable models. The same has been shown in the results of this study for multi-rainfall sites. Thus, inflows to the lake will be modelled as follows:

$$
\Delta \mathbf{I}=\mathbf{f}(\mathbf{R})+\mathbf{f}(\mathbf{G})
$$


where $\Delta \mathbf{I}$ is a column vector of the total lake inflows during the flood event at multi-lakes' sites, $\mathbf{f}(\mathbf{R})$ is a column vector of power functions of rainfall at multi-rainfall sites and $\mathbf{f}(\mathbf{G})$ is a column vector of functions of river flows going into the lakes, or draining the surrounding catchments.

For the best projection of $\Delta \mathbf{L}$ on $\mathbf{f}(\mathbf{R}), \mathbf{f}(\mathbf{G})$ and $\Delta \mathbf{Q},\{\Delta \mathbf{L}-\mathbf{f}(\mathbf{R})-\mathbf{f}(\mathbf{G})+\Delta \mathbf{Q}\}$ should be orthogonal to $\mathbf{f}(\mathbf{R})+\mathbf{f}(\mathbf{G})-\Delta \mathbf{Q}$. In Hilbert space, this is expressed as

$$
\text { Taking } X=\left[\begin{array}{l}
R \\
G \\
Q
\end{array}\right] \text {, and } \begin{array}{r}
<\Delta \mathbf{L}-\mathbf{f}(\mathbf{R})-\mathbf{f}(\mathbf{G})+\Delta \mathbf{Q}, \mathbf{f}(\mathbf{R})+\mathbf{f}(\mathbf{G})-\Delta \mathbf{Q}>=\mathbf{0} \\
\mathbf{f}(\mathbf{X})=\propto \boldsymbol{X}=\sum_{1}^{n} \propto_{i} \boldsymbol{X}_{i}
\end{array}
$$

where $\alpha$ is a row vector of parameters, and $\mathbf{X}$ is a column vector of functions of rainfall at each site $R_{i}$, river flows for each river site $G_{i}$ draining a catchment of the region, and outflows of each lake $Q_{i}$. The negative sign for $Q$ is not necessarily included, as the parameter estimation process should produce the right sign for the contribution of this variable. Equation 5 can be re-written as follows:

$$
<\Delta \mathrm{L}-\propto X, X>=\mathbf{0}
$$

The application of eqn 7 would produce $n$ equations in the parameters $\alpha$, where $n$ is the total number of rainfall sites and the inflow/outflow sites involved in the modelling process. These equations can be solved simultaneously to obtain the values of the parameters $\alpha$ as a function of statistical properties of the time series $\Delta \mathbf{L}$ and $\mathbf{X}$.

The solution of (7) can be expressed, in matrix form, as follows:

$$
\propto=\left(X^{T} X\right)^{-1} X^{T} \Delta L
$$

In case $\left(\boldsymbol{X}^{T} \boldsymbol{X}\right)^{-1}$ is singular, there will be infinite solutions to (8). However, by the uniqueness of the projection theorem, all of them will produce the same forecast [14].

The projection theorem guarantees that the model provided by (8) will produce coefficients of functions $\mathbf{f}\left(\mathbf{R}_{\mathbf{t}}\right), \mathbf{f}(\mathbf{G})$ and $\mathbf{f}(\mathbf{Q})$ for the best forecasts of $\Delta \mathbf{L}$. Of course, the type of these functions is not known, and part of the analysis carried out here is to obtain the best estimate of these functions. In the case of a linear relationship, the power of $R$ is 1 , and the power can be 0 for a constant parameter (intercept). There are two different cases to be considered here. The first case is the total lake rise (inflow) due to the total rainfall of an event. This is required in the case of a long-term forecast, when an event is expected to hit the region with an estimated total rainfall at a selected site, e.g. on the second day or two days later, and of course river flows draining these catchments are not observed or known yet. In this case, the real rainfall of this event is not observed yet, but it is important to forecast the impact of this event on the potential flooding of Queenstown or Wanaka. The other case is flood forecasting during the event itself, and in this case one forecasts the cumulative lake rise at both lakes after several hours (forecast time) due to the observed cumulative rainfall at the selected rainfall sites.

Case 1: the total lake rise due to the total rainfall

Figures 2 and 3 present the relationship between the total rainfall of 23 events and the corresponding total lake rise. The figures show that a linear relationship is quite suitable to 


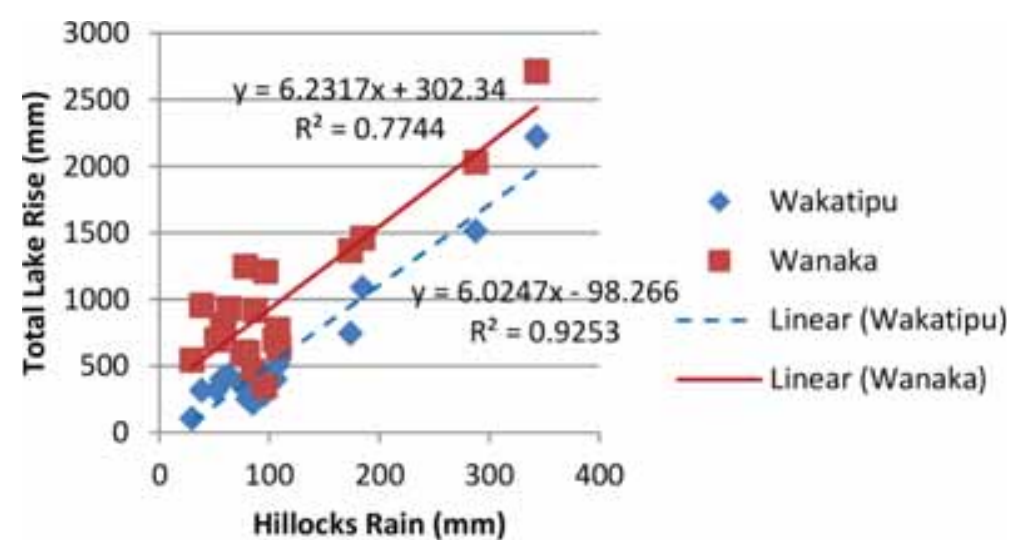

Figure 2: The total rainfall at the Hillocks and Lake Wakatipu rise.

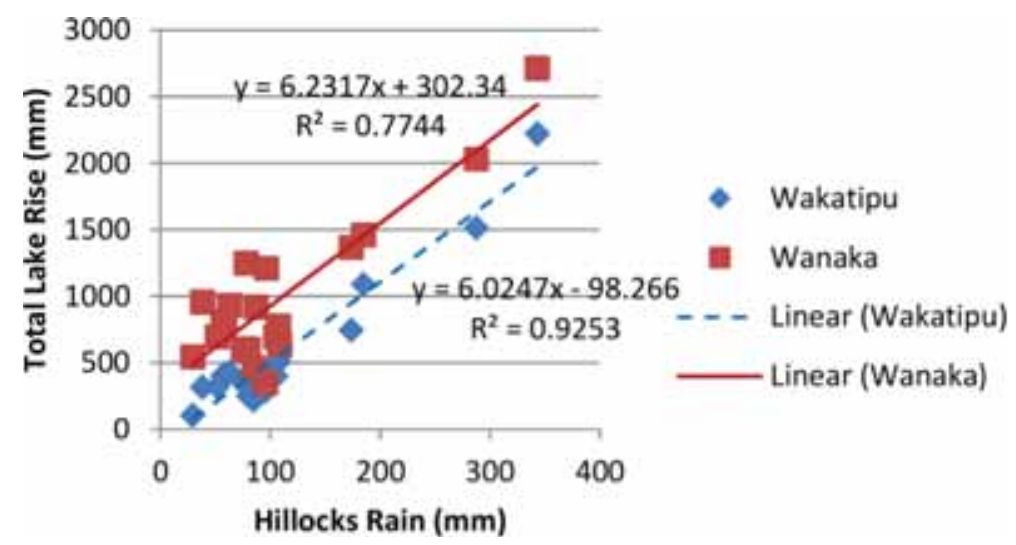

Figure 3: The total rainfall at Makarora and Lake Wanaka rise.

represent this relationship. It is quite clear from Fig. 2 that the total rise of Lake Wakatipu is well represented by a linear relationship of the total rainfalls at the Hillocks $\left(R^{2}=0.93\right)$, whereas this is not the case for Lake Wanaka. Makarora rainfall site offers a significantly improved linear relationship to the total rise of Lake Wanaka $\left(R^{2}=0.93\right)$ compared with the Hillocks rainfall $\left(R^{2}=0.8\right)$. These results indicate the importance of carrying out the analysis to choose the right rainfall sites to select for the modelling process. Figures 4 and 5 show the linear relationship for the multivariate case. Both the lakes have slightly improved their relationship with rainfall at the selected sites. However, the figures again confirm the fact that the wrong choice of rainfall sites would result in an unreliable forecast model. It should be mentioned that, in this study, other alternatives for rainfall sites were included, but only cases that improved the linearity of the relationship are presented.

Note that the variable $x$ of the trend line in Figs 4 and 5 is the weighted average of the total rain at several rainfall sites according to the weights of the projection of lake rise onto the total rainfall of these sites. Moreover, the projected weighted coefficients of the selected rainfall sites are not the same values for both lakes. For instance, in Fig. 4, the graphs shown are for the fitted parameters for Lake Wakatipu, not for Lake Wanaka, and that is why it shows much higher determination coefficient for Lake Wakatipu than for Lake Wanaka, and the opposite is true for Fig. 5. The cases where the projection process produced negative 


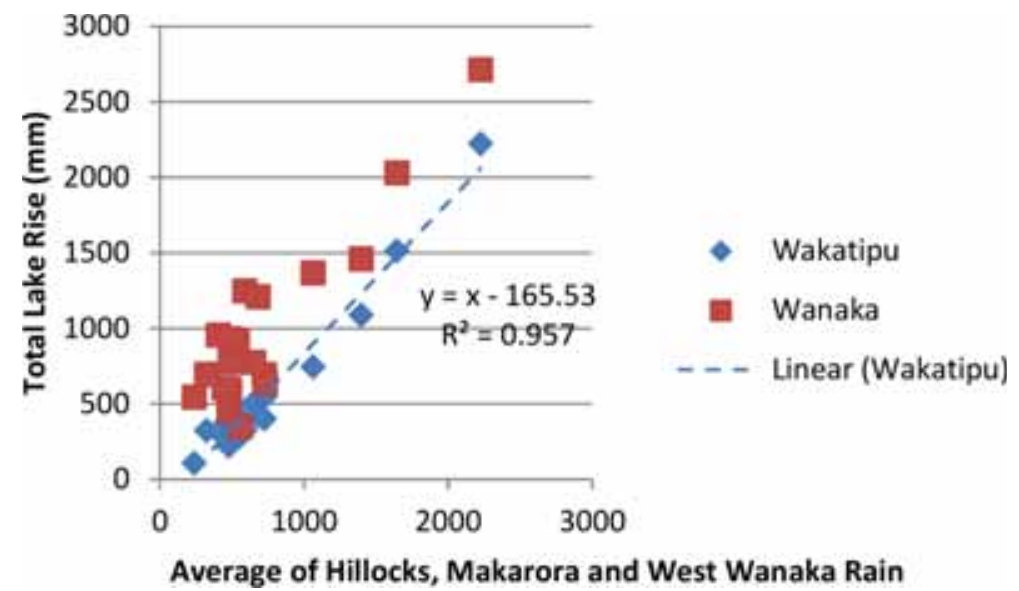

Figure 4: The average weighted rainfalls and Wakatipu level rise.

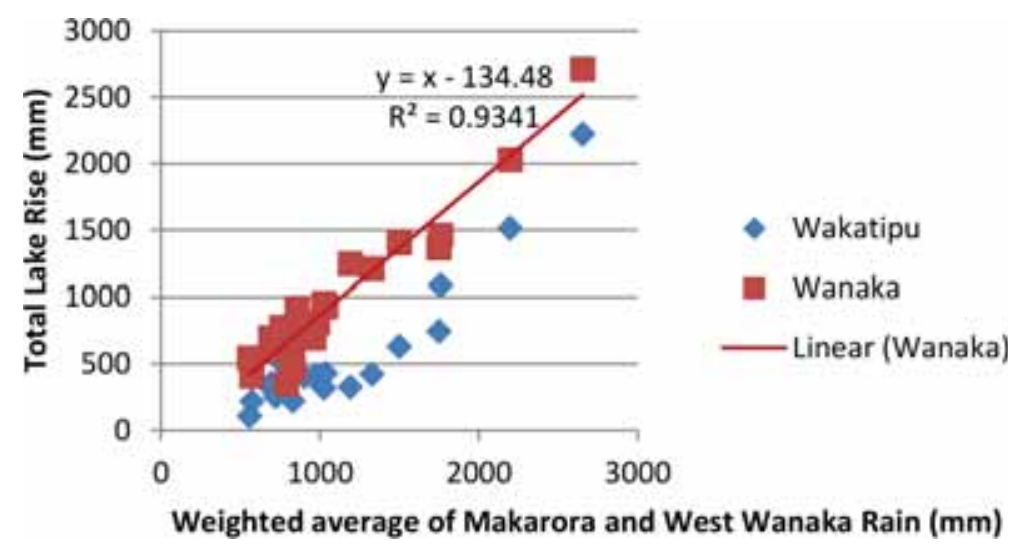

Figure 5: The average weighted rainfalls and Wanaka level rise.

coefficients for any of the rainfall sites were excluded, as one would consider these coefficients to represent the contribution of this rainfall site to the lake under study. The models derived from this study are as follows:

$$
\left[\begin{array}{l}
\Delta L(\text { Wakatipu }) \\
\Delta L(\text { Wanaka })
\end{array}\right]=\left[\begin{array}{lll}
2.54 & 1.42 & 3.72-165 \\
0.00 & 7.13 & 1.69-134
\end{array}\right]\left[\begin{array}{c}
H \\
M \\
W \\
1
\end{array}\right]
$$

where the total rainfall of the event at the Hillocks is $H$, at Makarora is $M$ and at West Wanaka is $W$.

Case 2: forecast during the rainfall event

Mohssen and Goldsmith [13] showed that a lag of 10 hours produces a good linear relationship between the cumulative Lake Wakatipu rise and cumulative rainfall at the Hillocks since the start of the rainfall events. As shown in Fig. 6, the optimum correlation between the cumulative increase in Lake Wanaka rise and the cumulative rainfall since the start of the rainfall event is 


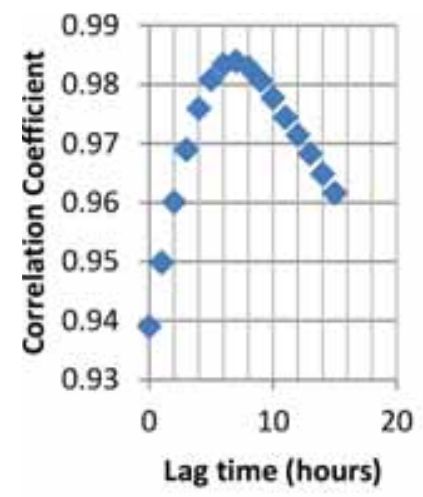

(a) November 1999 Event

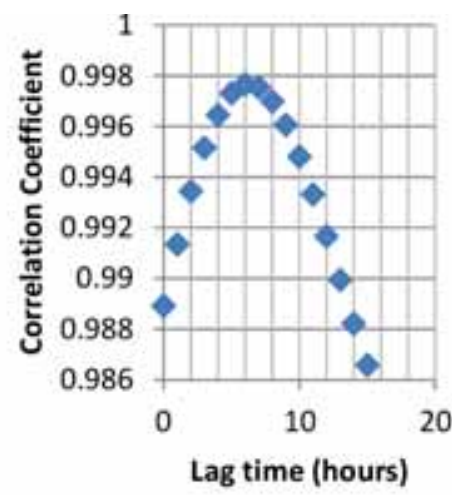

(b) April 2010 Event

Figure 6: The lagged correlations between the cumulative rain and Lake Wanaka rise.

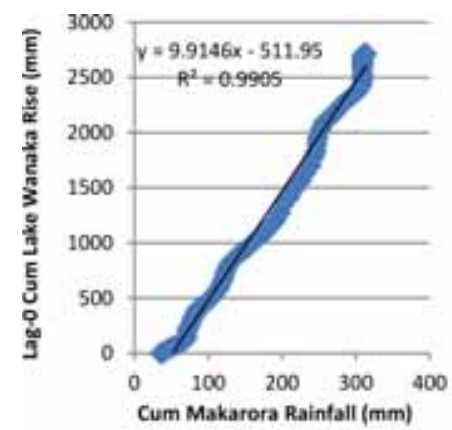

(a) Lag-0

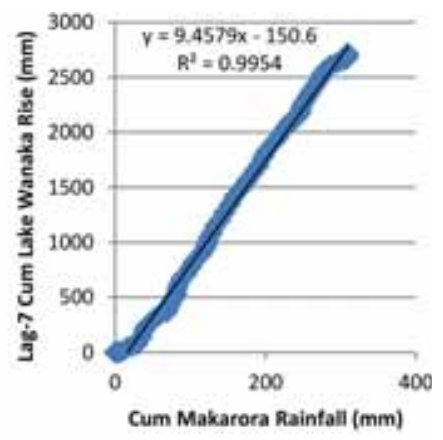

(b) Lag-7 hrs

Figure 7: The lagged correlations between the cumulative rain and Lake Wanaka rise.

7 hours. Figure 7 confirms that the linear relationship exists between the cumulative rainfall and the cumulative Lake Wanaka rise, and that the use of lag 7 hours significantly improved this linear relationship, which will definitely improve any modelling process. The results of Fig. 7 show the effectiveness of this new technique in improving the derived model.

Knowing that function $\mathbf{f}(\mathbf{R})$ of eqn 6 is linear and that $\mathbf{f}(\mathbf{Q})$ should be linear as it represents the sum of lakes' outflows, then function $\mathbf{f}(\mathbf{G})$ is also assumed linear. The projection equation (eqn 8) was applied to the 23 events to estimate the matrix of parameters $\alpha$. Thus, the multivariate model for hourly forecast of Lake Wakatipu and Lake Wanaka levels is

$$
\left[\begin{array}{l}
\Delta L(\text { Wakatipu }) \\
\Delta L(\text { Wanaka })
\end{array}\right]=\left[\begin{array}{cccccccc}
3.1 & 0 & 2.67 & 0 & 0.75 & 0 & -0.67 & 0 \\
0 & 4.6 & 0 & 1.7 & 0.78 & 0.57 & 0 & -0.49
\end{array}\right]\left[\begin{array}{c}
H \\
M \\
P \\
W \\
\text { Dart } \\
\text { Mat } \\
\text { Wak } \\
\text { LWan }
\end{array}\right]
$$


where Dart stands for the flows of the Dart River, which drains the catchment of Lake Wakatipu, Mat stands for the flows of the Matukituki River, which drains the catchment of Lake Wanaka, $P$ stands for rainfall at Peats Hut, Lwak and LWan are the outflows of Lake Wakatipu and Lake Wanaka, respectively, and $H, M$ and $W$ are as defined previously for eqn 9 .

The determination coefficient for the fitted model is 0.96 and 0.98 , while the Filliben correlation coefficient is 0.98 and 0.99 for Lake Wakatipu and Lake Wanaka, respectively.

Figures 8 and 9 show the results of the calibration of the multivariate model to both Lake Wakatipu and Lake Wanaka. The figures show that the simulated rises of Lake Wakatipu and Lake Wanaka levels by the fitted multivariate model for the 23 events used in the calibration process match well with the observed rises. These events are separate events and are not a continuous series of the rise of lake levels. The model sometimes overestimates the observed

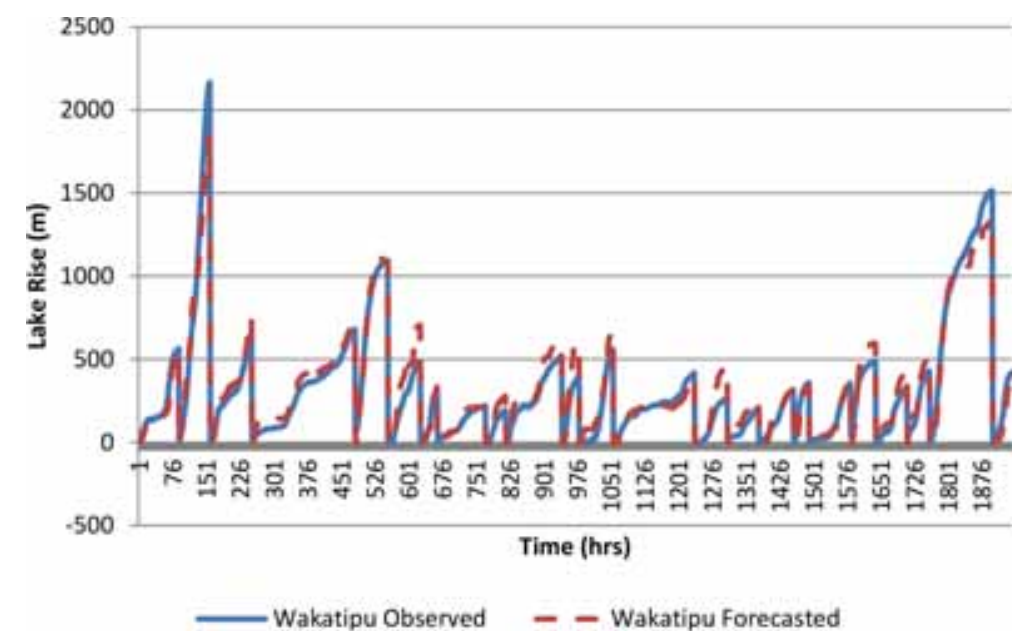

Figure 8: The observed vs. simulated Wakatipu level rise for the 23 events.

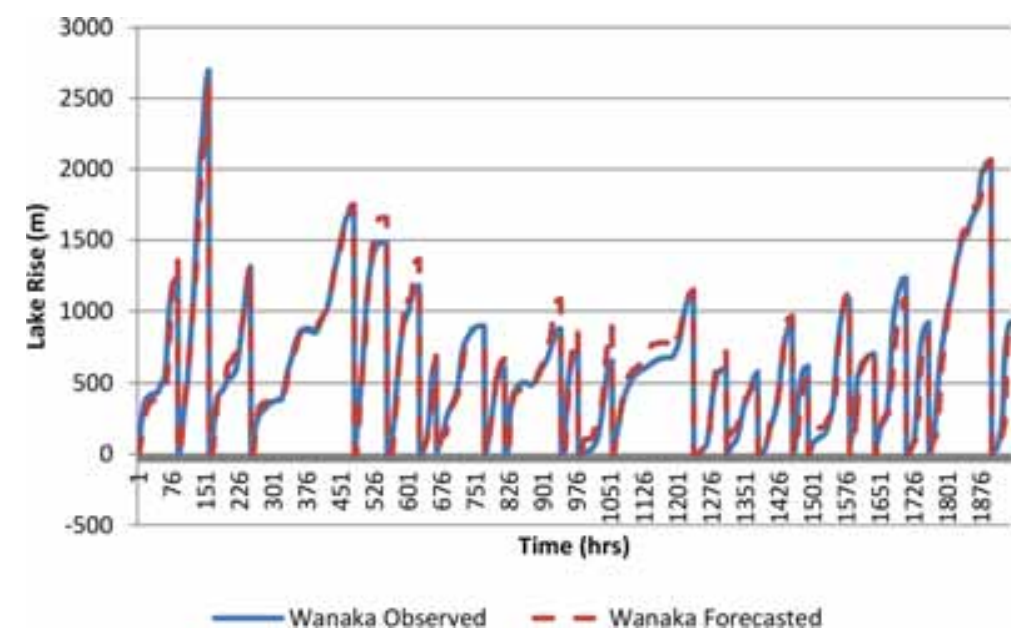

Figure 9: The observed vs. simulated Wakatipu level rise for the 23 events. 
rise of lake levels, and in other cases it underestimates it; however, the general simulation of such a complex hydrologic process is quite well.

\section{MODEL TESTING}

The validation of the fitted models was carried out by applying the model to rainfall events that were not included in its calibration. These two events were observed in November 2001 and December 2010, respectively. Table 2 shows the forecasted total lake rise $v s$. the observed rise for the two events, whereas Figs 10 and 11 show the application of the fitted model to forecast hourly cumulative lake rise with a lead time of 10 hours for Lake Wakatipu and 7 hours for Lake Wanaka. Figure 11 shows that the model forecasted perfectly well the December 2010 event for Lake Wanaka, in fact much better than the simulation of many events in the calibration process. It is usually difficult to forecast events with that accuracy during all the time of the event. However, the model did not do as well for Lake Wakatipu forecast. However, still as a forecast and not part of the calibration process, the model performed satisfactorily for such a complex hydrologic process.

\section{CONCLUSIONS}

A multivariate model has been developed to forecast flood levels for Lake Wakatipu and Lake Wanaka in the South Island of New Zealand. Two models have been derived in this research based on the projection theorem to obtain the optimum projection of the lake rises based on the gauged hydrologic variables available in the catchments area. The first model forecasts the total increase in lake rise based on the total forecasted/observed rainfalls at the selected sites in the catchment areas for both lakes. The derived multivariate model improved the determination

Table 2: The observed $v s$. forecasted total lake rise $(\mathrm{mm})$.

\begin{tabular}{lcccc}
\hline Event date & Lake & Observed & Forecast & \%Error \\
\hline November & 1 & 341 & 437 & 28 \\
2001 & 2 & 583 & 657 & 12.7 \\
December & 1 & 503 & 564 & 12 \\
2010 & 2 & 1335 & 1348 & 1 \\
\hline
\end{tabular}

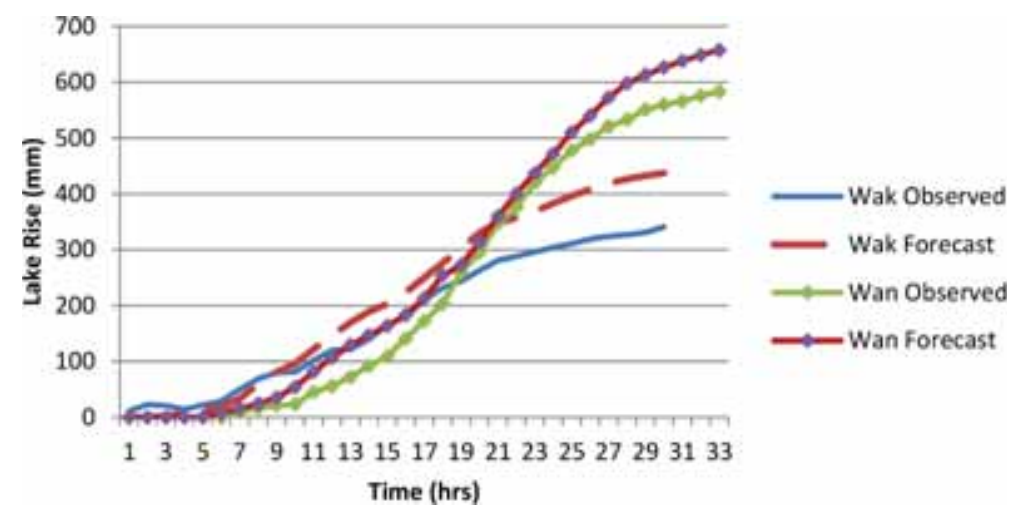

Figure 10: The observed $v s$. forecasted cumulative lake rises for the rainfall event November 2001. 


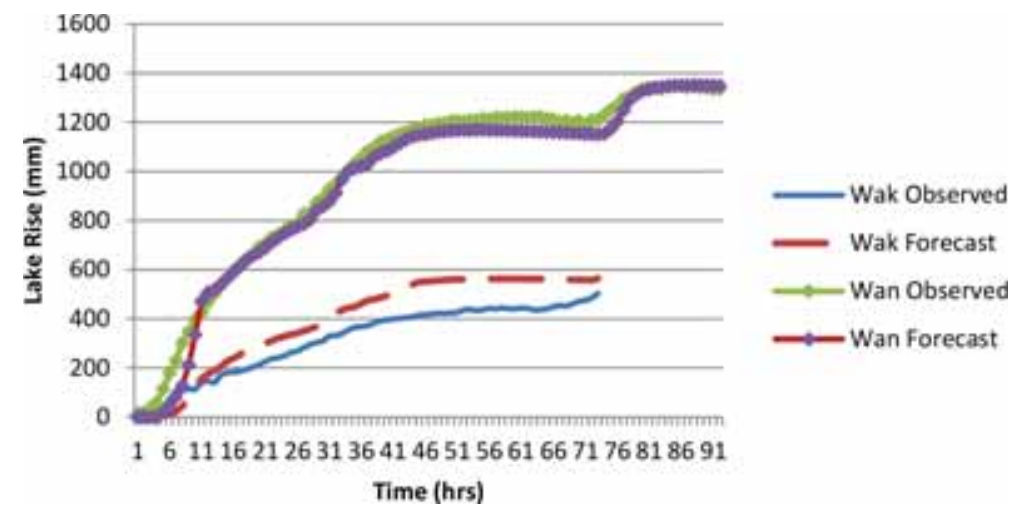

Figure 11: The observed vs. forecasted cumulative lake's rise for the rainfall event December 2010.

coefficient of the simulation, which would improve the accuracy of the forecasted lake levels. The second model forecasts the lake rise of both lakes during an event based on the cumulative rainfalls and flows at selected rainfall and flow sites in the catchment area, in addition to the outflows of the lakes. The analysis of lagged correlations between the cumulative/total lake rise and the cumulative/total rainfalls at the selected sites proved to be vital to estimate the optimum lag and to identify the function of the rainfall, which is used in the projection equations. The projection equations guarantee that the produced model would produce the best forecasts. The derived model proved that it can be used for flood forecast of lake levels, with accuracy ranging between 1 and $28 \%$. The developed models can be used either for a shortterm forecast during the flood event with a lead time of 10 and 7 hours for Lake Wakatipu and Lake Wanaka, respectively, or they can be used for a long-term forecast based on the forecasted total rains at the selected sites. This modelling technique is unique and easy to apply and adds a new approach to the literature of flood modelling of lakes' levels.

\section{REFERENCES}

[1] Bye, P. \& Horner, M., Easter 1998 Floods Report by the Independent Review Team to the Board of the Environmental Agency, Vol. 1, Environmental Agency: Bristol, 1998.

[2] Demeritt D., Cloke, H., Pappenberger, F., Thielen, J., Bartholmes, J. \& Ramoset, M.-H. Ensemble predictions and perceptions of risk, uncertainty, and error in flood forecasting. Environmental Hazards, 7, pp. 115-127, 2007. doi: http://dx.doi.org/10.1016/j. envhaz.2007.05.001

[3] Jowitt, P.W., A conceptual system model of rainfall-runoff on the Haast River. Journal of Hydrology, New Zealand, 38(1), pp. 121-144, 1999.

[4] Moore, R. et al., Forecasting for flood warning. C.R. Geoscience, 337, pp. 203-217, 2005. doi: http://dx.doi.org/10.1016/j.crte.2004.10.017

[5] Vaziri, M., Predicting Caspian Sea surface water level by ANN and ARIMA models. Journal of Waterway, Port, Coastal. Ocean Engineering, 123(4), pp. 158-162, 1997. doi: http://dx.doi.org/10.1061/(ASCE)0733-950X(1997)123:4(158)

[6] Tiwari, M.K. \& Chatterjee, C., Development of an accurate and reliable hourly flood forecasting model using wavelet-bootstrap-ANN (WBANN) hybrid approach. Journal of Hydrology, 394, pp. 458-470, 2010. doi: http://dx.doi.org/10.1016/j.jhydrol.2010.10.001 
[7] Chen, S.H., Lin, Y.H., Chang, L.C. \& Chang, F.J., The strategy of building a flood forecast model by neuro-fuzzy network. Journal of Hydrological Processes, 20(7), pp. 1525-1540, 2006. doi: http://dx.doi.org/10.1002/hyp.5942

[8] Kisi, O., et al., Forecasting daily lake levels using artificial intelligence approaches. Computers \& Geosciences, [7], 2011. doi: http://dx.doi.org/10.1016/j.cageo.2011.08.027

[9] Talebizadeh, M. \& Moridnejad, A., Uncertainty analysis for the forecast of lake level fluctuations using ensembles of ANN and ANFIS models. Expert Systems with Applications, 38, pp. 4126-4135, 2010. doi: http://dx.doi.org/10.1016/j.eswa.2010.09.075

[10] Ondimu, S. \& Murase, H., Reservoir level forecasting using neural networks: Lake Naivasha. Biosystems Engineering, 96(1), pp. 135-138, 2007. doi: http://dx.doi.org/ 10.1016/j.biosystemseng.2006.09.003

[11] Ozgur Kisi, O., Shiri, J. \& Nikoofar, F., Forecasting daily lake levels using artificial intelligence approaches. Computers \& Geosciences, 41, pp. 169-180, 2012. doi: http:// dx.doi.org/10.1016/j.cageo.2011.08.027

[12] McSaveney, E., Floods - New Zealand's Number One Hazard, TeAra - The Encyclopedia of New Zealand, updated 2-Mar-09, 2009

[13] Mohssen, M. \& Goldsmith, M., Flood forecasting of lake levels: A new concept. International Journal of Safety and Security Engineering, 1(4), pp. 363-375, 2011. doi: http://dx.doi.org/10.2495/SAFE-V1-N4-363-375

[14] Brockwell, P.J. \& Davis, R.A., Time Series: Theory and Methods, Springer-Verlag: New York Inc., pp. 46-51, 1991.

"This is a revised version of the paper published in WIT Transactions on Ecology and The Environment, Vol 159, (C) 2012 WIT Press, www.witpress.com, ISSN 1743-3541 (on-line), doi: 10.2495/FRIAR120101." 